\title{
АКТУЕЛНОСТИ
}

Mr Atila Dudaš

asistent Pravnog fakulteta u Novom Sadu

\section{O PREDNACRTU ZAKONA O ZADUŽBINAMA I FONDACIJAMA*}

\section{Opšti seminar za privatno pravo Pravnog fakulteta u Novom Sadu}

U okviru doktorskih studija „Privatno pravo”, na Pravnom fakultetu Univerziteta u Novom Sadu marta 2009. godine održan je Opšti seminar za privatno pravo, posvećen Prednacrtu Zakona o zadužbinama i fondacijama. ${ }^{1} \mathrm{Na}$ seminaru su učestvovali nastavnici i saradnici Univerziteta u Novom Sadu, studenti doktorskih studija, kao i stručnjaci iz prakse. Opšti seminar su vodile dr Marija Salma i dr Radenka Cvetić, vanredni profesori na Katedri građanskopravnih nauka Pravnog fakulteta u Novom Sadu.

Rad zadužbina, fondacija i fondova u Republici Srbiji reguliše Zakon o zadužbinama, fondacijama i fondovima iz $1989,{ }^{2}$ akt koji prema opštoj oceni više ne odgovara promenjenim društvenim odnosima i, prema rečima redaktora Prednacrta, ne predstavlja zadovoljavajući pravni okvir za razvoj zadužbinarstva i delovanje fondacija. Brojne su primedbe koje se mogu uputiti važećem Zakonu:

- Zakon predviđa zadužbinu, fondaciju i fond, kao oblike u kojima se ideja zadužbinarstva realizuje,$^{3}$ ali se klasifikacija zasniva na konceptima društvene svojine i društveno-pravnog lica, ${ }^{4}$ kategorijama koje više ne postoje u našem pravnom poretku.

* Rad primljen: 06. 05. 2009.

1 Tekst Prednacrta Zakona o zadužbinama i fondacijama, sa obrazloženjem osnovnih instituta i novina koje Prednacrt predviđa, dostupan je na internet adresi Ministarstva kulture Republike Srbije http://www.kultura.sr.gov.yu/?jez=scfp=56

2 Zakon o zadužbinama, fondacijama i fondovima, Službeni glasnik SRS, br. 59/89.

3 V. čl. 1. Zakona o zadužbinama, fondacijama i fondovima.

4 V. čl. 4. Zakona o zadužbinama, fondacijama i fondovima. 
- Osnivač zadužbine može biti samo fizičko lice, ${ }^{5}$ čime se onemogućava razvoj tzv. korporativnog zadužbinarstva.

- Zadužbina, fondacija i fond mogu se osnovati samo ako u trenutku osnivanja raspolažu sredstvima dovoljnim za ostvarenje ciljeva radi kojih se osnivaju. Ovaj uslov punovažnog osnivanja je preterano rigorozan, s jedne, i daje neopravdano velika diskreciona ovlašćenja organu koji vrši registraciju da ceni da li je ovaj (imovinski) zahtev u konkretnom slučaju ispunjen, s druge strane. ${ }^{6}$

- Osnivanje zadužbina, fondacija i fondova je moguće samo radi opštekorisnih ciljeva i vrši se po koncesionom sistemu (sistemu odobrenja), umesto normativnog sistema koji je više u duhu građanskog društva. Prema tome, registarski organ može da ceni ne samo da li zadužbina, fondacija i fond ispunjavaju propisane uslove za osnivanje i upis u registar, već i celishodnost njihovog osnivanja.?

Prednacrt Zakona o zadužbinama i fondacijama predviđa brojne novine $\mathrm{u}$ odnosu na rešenja prihvaćena u važećem Zakonu.

- Predviđaju se dva statusno-pravna oblika: zadužbina i fondacija. ${ }^{8}$ Zadužbinu i fondaciju mogu osnovati i pravna i fizička lica. ${ }^{9} \mathrm{Za}$ osnivanje zadužbine, međutim, osnivač treba da obezbedi osnovnu imovinu u vrednosti od najmanje 50.000 evra, ako se osniva zadužbina koja deluje u javnom interesu, odnosno 100.000 evra, ako deluje u privatnom interesu. ${ }^{10} \mathrm{Za}$ osnivanje fondacije nije predviđena minimalna vrednost osnovne imovine, ali se ona ne može osnovati u privatnom interesu. ${ }^{11}$

- Ciljevi osnivanja zadužbina mogu biti opštekorisni i privatni, ali su uslovi za osnivanje zadužbine koja ima privatne (neimovinske) ciljeve stroži (osnivač treba da obezbedi osnovnu imovinu u vrednosti od najmanje 100.000 evra). Prednacrt precizno definiše šta se smatra opštekorisnim, a šta privatnim ciljevima radi kojih se može osnovati zadužbina i fondacija. ${ }^{12}$ Taksativno su predviđeni i ciljevi koji se smatraju nedopuštenim. ${ }^{13}$

- Za razliku od važećeg Zakona, Prednacrt sadrži detaljne odredbe o postupku osnivanja, upisa u registar i o unutrašnjoj organizaciji zadužbine i fondacije. ${ }^{14}$

- Prednacrt propisuje posebne standarde dužne pažnje upravitelja i članova upravnog odbora zadužbine i fondacije, odgovornost za povredu tih standarda, ${ }^{15}$ kao i institut prodora kroz pravno lice. ${ }^{16}$

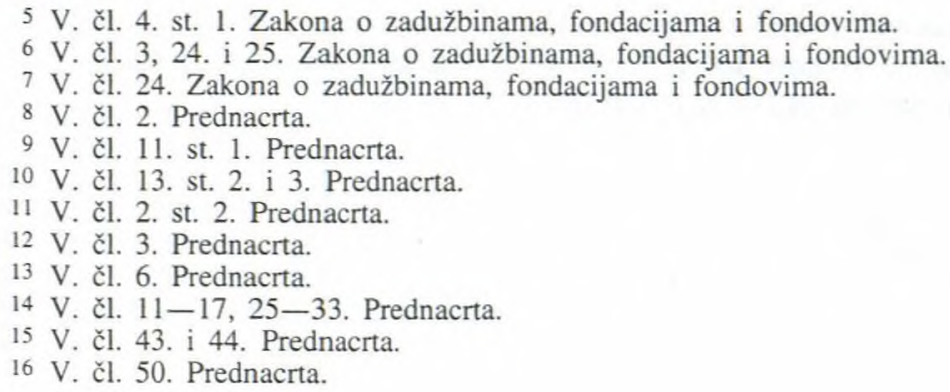


Uvodna izlaganja podneli su koordinatori Opšteg seminara, prof. dr Radenka Cvetić i prof. dr Marija Salma.

Profesorka Radenka Cvetić je na početku svog izlaganja istakla da u okviru doktorskih studija Privatno pravo, Pravni fakultet oživljava opšti seminar kao oblik rada koji omogućava angažovanje ne samo nastavnika, saradnika i studenata, već i šire stručne javnosti u raspravljanju različitih teorijskih i praktičnih pitanja. Naime, do kraja 80-ih godina XX veka uspešno je funkcionisao Opšti seminar građanskog prava pod rukovodstvom dr Borivoja Starovića i dr Jožefa Salme, profesora Katedre građanskopravnih nauka. Svojevremeno su na Opštem seminaru razmatrana ne samo interesantna, već i tada vrlo aktuelna pitanja, kao što su, na primer, novčane obligacije - nominalizam ili valorizam, teze za izradu Zakona o vanparničnom postupku Vojvodine, obligaciona i stvarnopravna pitanja u izvršnom postupku, itd.

Zadužbine i fondacije su aktuelna pitanja sadašnjice ne samo zbog njihovog značaja već i zbog činjenice da se odvija javna rasprava o Prednacrtu novog Zakona o zadužbinama $i$ fondacijama. U traženju adekvatnije regulative za razvoj zadužbinarstva i delovanje fondacija, nego što je to važeći Zakon o zadužbinama, fondacijama i fondovima iz 1989. godine, došlo se do Prednacrta novog zakona. Izradila ga je Radna grupa koju su formirali Ministarstvo kulture Republike Srbije i Balkanski fond za lokalne inicijative. Rad na izradi Prednacrta je trajao osam meseci i završen je u julu 2008. godine. Na kraju svog izlaganja prof. Cvetić je istakla da je jedan od osnovnih kvaliteta Prednacrta to što se po principu numerus clausus predviđaju nedopušteni ciljevi osnivanja, čime se znatno smanjuju diskreciona ovlašćenja registarskog organa u određivanju dozvoljenih ciljeva radi kojih se može osnovati zadužbina i fondacija, s jedne, ali se uvodi i mogućnost osnivanja privatnih (porodičnih) zadužbina, s druge strane, što je u svakom pogledu velika novina (ne samo u odnosu na važeći Zakon, nego i na ranije važeću regulativu u Kraljevini Srbiji i Jugoslaviji).

Profesorka Marija Salma se u svom izlaganju osvrnula na pojedina normativna rešenja Prednacrta. Tako, ona ističe da bi se u definiciji zadužbine i fondacije ${ }^{17}$ moglo dodati da zadužbina trajno služi ostvarenju javnog ili privatnog interesa, dok se fondacija, pak, osniva da u određenom vremenskom periodu služi ostvarivanju javnog interesa. Drugo, Prednacrt ne predviđa mogućnost pobijanja osnivanja zadužbine od strane lica koja za to mogu imati pravni interes, ${ }^{18}$ a to su, po pravilu, naslednici i poverioci osnivača. Iz ovog razloga, profesorka Salma smatra da bi trebalo dati mogućnost naslednicima osnivača zadužbine da pobijaju njegovu izjavu poslednje volje o osnivanju zadužbine. Izjavu o pobijanju naslednici bi morali dati najkasnije prilikom davanja svoje nasledničke izjave. Slično, pravo pobijanja bi trebalo da imaju i poverioci osnivača, koji bi to svoje

17 V. čl. 2. Prednacrta.

18 V. čl. 14. i 15. Prednacrta. 
pravo ostvarili pokretanjem parničnog postupka. Treće, u pogledu imovine i načina sticanja imovine zadužbine i fondacije, ${ }^{19}$ profesorka Salma predlaže preciziranje teksta Prednacrta da se nepokretna imovina zadužbine može nalaziti i u inostranstvu, i da bi novčana sredstva, kao deo imovine zadužbine, trebalo da se polože na račun zadužbine u Republici Srbiji. I, na kraju, u odredbi Prednacrta o uslovima i načinu brisanja zadužbine $\mathrm{i}$ fondacije iz registra, ${ }^{20}$ trebalo bi dodati konstataciju da je rešenje o prestanku zadužbine, brisanjem iz registra, osnov za uknjižbu promene vlasništva u zemljišnim knjigama ili u katastru nepokretnosti.

Dr Jožef Salma, redovni profesor na Katedri građanskopravnih nauka Pravnog fakulteta u Novom Sadu, u svom izlaganju uporedio je normativna rešenja iz Prednacrta sa regulativom zadužbina i fondacija u uporednom pravu. Naglasio je da u svetu i u Evropi postoje različiti tipovi fondacija. Njihova osnovna podela na javne i privatne fondacije izvršena je u zavisnosti od toga da li služe individualnim (privatnopravnim) ili opštim, odnosno zajedničkim ciljevima, pri čemu ovo razgraničenje ni u jednoj državi nije oštro i bez izuzetaka izvršeno. Tako, i javne fondacije mogu podržavati ,privatne" ciljeve (kao što je, na primer, školovanje talentovanih studenata), s jedne, ali i privatne fondacije mogu poslužiti „opštim" ciljevima (kao što su, na primer, pružanje pomoći i nege licima zaostalim u razvoju, licima obolelim od teških bolesti, i sl.), s druge strane. Ciljevi i jednih i drugih fondacija, prema tome, mogu biti humanitarni, kulturni, obrazovni, naučni i dr. U moguće ciljeve fondacija se svakako može svrstati i zaštita ljudskih, građanskih i manjinskih prava. Javne i privatne fondacije se mogu razlikovati i po osnivačima. Fondacije kojima se ostvaruju i javni interesi (na primer, Srpsko lekarsko društvo, Naučno društvo vojvođanskih Mađara itd.) mogu da imaju sufinansiranje i iz budžetskih sredstava. U periodu tranzicije postoji naglašena potreba za delatnošću privatnih fondacija i udruženja građana (civilni sektor), imajući u vidu da preuzimaju sve veći deo delatnosti od javnog interesa koji je pre bio u nadležnosti države. Država treba da ima liberalniji pristup osnivanju i obavljanju delatnosti i javnih i privatnih fondacija. Tako, prof. Salma, u pogledu pojedinih normativnih rešenja u Prednacrtu, predlaže da se omogući osnivanje kako trajnih, tako i privremenih fondacija, s jedne, i smanjenje vrednosti minimalne imovine potrebne za osnivanje zadužbina, s druge strane.

Dr Dušan Nikolić, redovni profesor na Katedri građanskopravnih nauka Pravnog fakulteta u Novom Sadu, posebnu pažnju je posvetio odredbama Prednacrta o privatnim zadužbinama, među koje spadaju i one koje se osnivaju isključivo u interesu sadašnjih i budućih članova jedne porodice (porodične zadužbine, Familienstiftung). Ukazao je na različit odnos prema tom pravnom institutu u zemljama romanskog i germanskog kruga, kao i na činjenicu da njegova recepcija nije uslov za ulazak u Evropsku

19 V. čl. 45. Prednacrta.

20 V. čl. 52. Prednacrta. 
uniju. Profesor Nikolić je zaključio da za sada ne treba uvoditi porodične zadužbine u pravni sistem Republike Srbije. U prilog tome je naveo brojne argumente. Tako, stvaranjem porodičnih zadužbina deo društvenog (nacionalnog) kapitala prelazi u kategoriju dobara mrtve ruke koja nije izložena tržišnoj utakmici. Izdvajanje zadužbinske imovine iz ukupne mase sredstava na tržištu, direktno ili indirektno, usporava ekonomski razvoj društva, nezavisno od toga da li se radi o razvijenim ili nerazvijenim zemljama. Problem je srazmerno veći u siromašnim tranzicionim društvima, u kojima postoji visok stepen socijalne raslojenosti. Ukoliko bi mali broj izuzetno bogatih porodica formirao porodične zadužbine, najveći deo kapitala u tranzicionim zemljama bi bio pretvoren u dobra mrtve ruke. Formiranjem porodičnih zadužbina trajno bi bila osigurana ekonomska i društvena moć svih sadašnjih i budućih članova pojedinih porodica, čime bi odnosi u društvu mogli da budu konzervisani, što bi sprečilo formiranje nove srednje klase koja je bitna za stabilnost društva. Većina građana, a posebno pripadnici mlađih generacija, izgubili bi perspektivu i poverenje u društvene institucije koje su do sada, makar i formalno, omogućavale svima da učestvuju u preraspodeli društvenog kapitala. Ako bi veći deo društvenog kapitala bio pretvoren u zadužbinsku imovinu pod isključivom kontrolom pojedinih porodica, bilo bi srazmerno manje sredstava za formiranje javnih zadužbina. U duhu ideje o razvoju civilnog društva, javne zadužbine bi u budućnosti trebalo da se staraju o mnogim javnim interesima, koji su trenutno u ingerenciji države. Ako države ne budu imale dovoljno sredstava u budžetu, a u međuvremenu ne budu formirane javne zadužbine, opšti napredak pojedinih tranzicionih društava i egzistencija mnogih građana biće dovedeni u pitanje, usled čega bi pojedini regioni, u dužem periodu, mogli da budu nestabilni. Formiranje porodičnih zadužbina u tranzicionim zemljama bi tako, na indirektan način, moglo negativno uticati na dinamiku i efekte integracionih procesa, koji treba da omoguće povezivanje društava sa različitim pravnim kulturama i razvoj civilnog društva.

Porodične zadužbine nisu deo srpske tradicije, ni u kulturnom, ni u pravnom smislu. U skladu sa načelima tradicionalnog srpskog zadužbinarstva, zadužbinska imovina treba da služi ostvarivanju javnih interesa. U pravnom sistemu Srbije, već čitav jedan vek, postoji negativan odnos prema porodičnim fideikomisima i sličnim pravnim institutima, među koje spadaju i porodične zadužbine. Srbija je opterećena ekonomskim i socijalnim problemima koji prate tranziciju, uključujući visok nivo socijalne raslojenosti stanovništva i nepostojanje srednje klase. Državni fondovi za zadovoljavanje javnih interesa su vrlo skromni, a duh tradicionalnog srpskog zadužbinarstva nije obnovljen. U takvim okolnostima liberalni odnos prema osnivanju porodičnih zadužbina, koji je u Prednacrtu iskazan kroz konstataciju da je dozvoljeno sve što nije zabranjeno ustavom i zakonom, jednostavno nije primeren realnosti i perspektivama društva u kome žive građani Srbije. Stav da su ,zadužbine samostalne u određivanju svojih ci- 
ljeva"21 sasvim je u skladu sa idejom zadužbinarstva. Međutim, on dobija bitno drugačiji smisao kada se dovede u vezu sa funkcijom privatnih zadužbina. Već na prvi pogled se stiče utisak da je Prednacrt pisan u interesu imućnih društvenih slojeva. Propisano je da se zadužbine mogu osnovati na neodređeno i određeno vreme, ${ }^{22}$ a odmah potom sledi konstatacija da se u slučaju neotklonjive sumnje smatra da su osnovane na neodređeno vreme. ${ }^{23}$ Zanimljivo je i to da je cenzus za osnivanje porodične zadužbine dvostruko veći od cenzusa koji je predviđen za javne zadužbine, i da iznosi 100.000 evra, ${ }^{24}$ što je za najveći broj građana veoma veliki iznos. Na osnovu toga bi se moglo zaključiti da bi osnivanje porodičnih zadužbina bila privilegija bogatih članova društva. Tekovina siromašnih porodica bi bila u pravnom prometu, a to znači da bi mogla da bude predmet novih preraspodela društvenog bogatstva. Redaktori Prednacrta su i sami zaključili da privatne (porodične) zadužbine ne postoje u svim zemljama Evropske unije i da bi se pravo na njihovo osnivanje moglo braniti (samo) in extenso, dakle ekstenzivnim tumačenjem prava na mirno uživanje vlasništva, zaštićenog Evropskom konvencijom o zaštiti ljudskih prava i osnovnih sloboda. Stvaranje normativne podloge za osnivanje porodičnih zadužbina nije uslov za prijem u članstvo Evropske unije. Srbija bi, po mišljenju prof. Nikolića, efikasnije odgovorila na izazove globalizacije i civilnog društva, ukoliko bi zadržala samo tradicionalni koncept (javne) zadužbine i pri tom podstakla razvoj zadužbinarstva.

Dr Gordana Kovaček-Stanić, redovni profesor na Katedri građanskopravnih nauka Pravnog fakulteta u Novom Sadu, takođe se osvrnula na pitanje privatnih zadužbina i istakla da je neophodno precizirati njihov pravni položaj da bi se moglo utvrditi da li se radi o porodičnom fideikomisu ili ne, s obzirom na moguću koliziju sa odredbama važećeg Zakona o nasleđivanju ${ }^{25}$ o ništavosti zaveštanja (testamenta). Naime, Zakon o nasleđivanju, između ostalog, predviđa da je ništava odredba zaveštanja, kojom zaveštalac određuje naslednika svom nasledniku ili isporukoprimcu, zabranjuje svom nasledniku ili isporukoprimcu da otuđi stvar ili pravo koje mu je ostavio ili kojom se zabranjuje ili ograničava deoba nasledstva. ${ }^{26}$ Prema tome, Zakon o nasleđivanju zabranjuje svaki vid porodičnog fideikomisa. S druge strane, profesorka Kovaček-Stanić smatra da bi u Prednacrtu bilo potrebno izvršiti preciziranje prava i obaveze izvršioca zaveštanja kada se radi o zadužbini koja se osniva zaveštanjem (testamentom), s obzirom na to da Zakon o nasleđivanju, na koji se Prednacrt pozi$v^{2},{ }^{27}$ ne sadrži takve odredbe. Profesorka Kovaček-Stanić je imala pri-

21 V. čl. 5. Prednacrta.

22 V. čl. 9. st. 1. Prednacrta.

23 V. čl. 9. st. 2. Prednacrta.

24 V. čl. 13. st. 3. Prednacrta.

25 Zakon o nasleđivanju, Službeni glasnik RS, br. 46/95. i br. 101/2003 — odluka Ustavnog suda RS.

26 V. čl. 159. Zakona o nasleđivanju.

27 V. čl. 11. st. 6. Prednacrta. 
medbe i u pogledu termina upotrebljenih u tekstu Prednacrta. Smatra da bi termin „bračni drug" u tekstu Prednacrta ${ }^{28}$ trebalo zameniti terminom „supružnik” u skladu sa Porodičnim zakonom iz 2005. godine, ${ }^{29}$ koji više ne koristi termin „bračni drug”. Termin „,izjava poslednje volje” u Prednacrtu ${ }^{30}$ bi trebalo zameniti izrazom ,testament” ili „zaveštanje”, u skladu sa terminologijom Zakona o nasleđivanju. I na kraju, termin „,maloletno lice”31 bi trebalo zameniti izrazom ,,poslovna sposobnost”, jer i maloletnik stariji od 16 godina može imati potpunu poslovnu sposobnost i tada imati i prava i obaveze po Prednacrtu.

Marko Knežević, asistent na Katedri građanskopravnih nauka Pravnog fakulteta u Novom Sadu, u svom izlaganju je naglasio da je kroz konstrukciju postupka za upis u Registar zadužbina i fondacija primetna težnja tvoraca Prednacrta da se osnivanje ovih pravnih lica što više olakša, što potvrđuje i odredba o odbacivanju prijave za upis. ${ }^{32}$ Pored tipičnih razloga za odbacivanje prijave za upis, onih koji se tiču procesnih nedostataka (na primer, prijava ne sadrži sve tražene podatke, nisu priloženi svi traženi dokazi i sl.), Prednacrt svrstava u ovu kategoriju i nedostatak pojedinih meritornih uslova za upis zadužbina i fondacija, čime oni zapravo postaju procesni uslovi. Tako, nedostatak koji se tiče distinktivnosti imena i simbola zadužbine i fondacije su potencijalni razlozi za odbacivanje prijave za upis. Na ovaj način Prednacrt olakšava zainteresovanim licima da osnuju zadužbine i fondacije, jer navedeni nedostaci neće automatski dovesti do odbacivanja prijave za upis, već će nadležni organ prvo poučiti stranku i ostaviti joj rok za ispravak prijave, pa će je odbaciti tek ako je stranka ne ispravi. S druge strane, upravo redakcija citiranog člana predstavlja nedostatak Prednacrta. Naime, logički redosled normi je pogrešan, jer se u prvom stavu govori o situacijama kada će se odbaciti prijava za upis, dok se u drugom stavu ipak navodi da će nadležni organ pre odbacivanja poučiti stranku i ostaviti joj rok za ispravak prijave. U takvoj procesnoj situaciji, ispravno bi bilo, uostalom kako je to inače i manir u drugim procesnim zakonima, da se prvo odrede nedostaci koji dovode do poučavanja stranke i ostavljanja roka za ispravak, a da se nakon toga odredi posledica za neuspelo poučavanje stranke. Na kraju, iako je sasvim nesporno da je postupak za upis u Registar zadužbina i fondacija upravni postupak, bilo bi ipak dobro da se izričito reguliše primena pravila opšteg upravnog postupka na njegove neregulisane delove. Time bi se, po mišljenju asistenta Kneževića, pojačala pravna sigurnost, te bi se i predupredile eventualne greške u praktičnoj primeni koje su inače identifikovane u praksi u situacijama postojanja relacije poseban postupak - opšti postupak.

Siniša Novković, student doktorskih studija na Pravnom fakultetu u Novom Sadu, isto tako je naglasio da je minimalni iznos osnovne imovine

\footnotetext{
28 V. čl. 40. Prednacrta.

29 Porodični zakon, Službeni glasnik RS, br. 18/2005.

30 V. čl. 25. st. 3. t. 6. Prednacrta.

31 V. čl. 37. st. 3. i 4. Prednacrta.

32 V. čl. 27. Prednacrta.
} 
propisane za osnivanje zadužbina previsoko postavljen. Zadužbina kao institucija počiva pre svega na principu dobročinstva, zadužbinarstva. Visokim novčanim cenzusom za osnivanje zadužbinarstvo postaje privilegija isključivo bogatih građana. Dalje, Prednacrtom je predviđeno da, ukoliko je osnovna imovina zadužbine izražena u stvarima ili pravima, procenu vrednosti takve imovine vrši sudski veštak, ${ }^{33}$ međutim, tekst Prednacrta ne predviđa ko predlaže ličnost sudskog veštaka u tom slučaju. Ako to radi osnivač zadužbine, da li postoji mehanizam kontrole priloženog nalaza veštaka o vrednosti osnivačke imovine? Sve su ovo pitanja na koja Prednacrt ne daje odgovor.

33 V. čl. 12. st. 2. Prednacrta. 